\title{
Overall and local effects of operating conditions in PEM fuel cells with dead-ended anode
}

\author{
Yupeng Yang ${ }^{\mathrm{a}}$, Xu Zhang ${ }^{\mathrm{a}}$, Liejin Guo ${ }^{\mathrm{a}, *}$, Hongtan Liu ${ }^{\mathrm{b}, *}$ \\ ${ }^{a}$ International Research Center for Renewable Energy, State Key Laboratory of \\ Multiphase Flow in Power Engineering, Xi' an Jiaotong University, Xi'an, Shaanxi \\ 710049, P R China \\ ${ }^{\mathrm{b}}$ Department of Mechanical and Aerospace Engineering, University of Miami, Coral \\ Gables, FL 33124, USA
}

Yupeng Yang

Tel.: +86298266 5591; fax: +862982669033

Email address: yyp1990@stu.xjtu.edu.cn (Y. Yang)

$\mathrm{Xu}$ Zhang

Tel.: +86298266 5591; fax: +862982669033

Email address: zhangxuxjtu@stu.xjtu.edu.cn (X. Zhang)

Liejin Guo *

Corresponding author. Tel.: +86298266 3895; fax: +862982669033.

Email address: lj-guo@mail.xjtu.edu.cn (L. Guo).

Hongtan Liu *

Corresponding author. Tel.: +86 298266 5591; +1 305284 2019; fax: +1 305284 2580 .

E-mail address: hliu@miami.edu (H. Liu). 


\begin{abstract}
Impurity Nitrogen and water accumulations in fuel cells with dead-ended anode can cause severe cell performance decline and fluctuations. In this work, both overall and local effects of fuel cell operating parameters, i.e., cathode humidity, air stoichiometry, hydrogen pressure and operating current density, have been experimentally studied under galvanostatic mode. A purge at the anode is automatically triggered when the cell voltage has decreased by $0.1 \mathrm{~V}$ and the mean purge interval, defined as the average time between two purges, is recorded as a characteristic parameter. Local current densities are measured to study the local effects and detailed local characteristics of the fuel cell. The experimental results show that mean purge intervals decrease with cathode inlet humidity and operating current density, and increase with inlet hydrogen pressure and air stoichiometry. The experimental results also show that the local current densities change very differently at different locations and impurities first accumulate near the end of the anode channel and then gradually progress upstream.
\end{abstract}

Keywords: PEM fuel cell, dead-ended anode, anode purge, anode impurity accumulation 


\section{Introduction}

Proton exchange membrane fuel cells (PEMFCs) have received much attention because of their high efficiency and zero emission. However, their cost and durability are still the main challenges to their commercialization [1]. Eonventionat Commonly-used PEM fuel cell system is usually equipped with an anode recirculation system. In such a system, hydrogen is supplied in excess and the non-reacted hydrogen is recirculated back to the fuel cell inlet by a hydrogen recirculation blower or an ejector. Although such a system can have high fuel utilization, the recirculation devices increase system complexity and lead to higher cost, especially for portable applications. To simplify the anode supply system, the dead-ended anode (DEA) configuration has been used [2-4]. During DEA operation, dry hydrogen is supplied through a pressure regulator installed at the fuel cell inlet and a normally-closed solenoid valve is installed at the outlet. Without the recirculation devices, the fuel cell system cost, volume and weight are all reduced [5-11]. However, during DEA operation, impurities (liquid water and nitrogen gas) can transfer through the membrane from the cathode to the anode and their accumulation may block hydrogen gas from reaching the catalyst, leading to local hydrogen starvation and decrease in cell performance [12-14]. Furthermore, of oxygen in the anode where hydrogen is starved may lead to high cathode potentials during a DEA operation. Local high cathode potentials hydrogen starvation can result in corrosion of the carbon support and thus lead to irreversible cell degradations [15-17]. To prevent the performance decline and irreversible degradation during DEA operation, anode purge is commonly used. Anode purges are usually accomplished by opening the solenoid valve at the anode outlet periodically. During anode purges, the accumulated water and nitrogen are swept out of the anode channel by fresh dry hydrogen. The purge frequency depends on the rates of water and nitrogen accumulation in the anode and the allowable amount of decrease in cell output.

It is well known that operating conditions have significant effects on water and nitrogen accumulation in the anode, and in recent years, significant efforts have been devoted to this issue both at the single cell level $[5,8,10,14,18]$ and at the stack level [11, 19]. Chen et al. [5] systematically investigated the operation characteristics of a single fuel cell with DEA under various operating parameters and their results showed that the cell performance decrease mainly resulted from water accumulation since pure oxygen was used in the cathode. Himanen et al. [10] studied the effect of hydrogen pressure with a planar free breathing PEM fuel cell and they found that 
higher hydrogen pressure could reduce anode side flooding. Nikiforow et al. [8] investigated the impact of cathode humidity and their results showed that higher cathode humidity led to more water accumulation in the anode. Lee et al. [14] observed water accumulation in the anode gas channel under various operating parameters with a transparent single fuel cell. Their experimental results showed that water accumulation decreased as air stoichiometry increased. Siegel et al.[18] investigated water accumulation in the anode using neutron radiography technology and their results showed that water accumulation increased with operating current density.

The effects of operating conditions on fuel cell stacks with DEA have also been investigated. Dumercy et al. [11] investigated the effect of operating current density in a 3-cell stack with DEA and found that there was not apparent decrease in stack voltage when the operating current density was lower than $400 \mathrm{~mA} \mathrm{~cm}^{-2}$. Sasmito et al. [19] studied the effect of air stoichiometry on the purging process with a 24-cell PEM fuel cell stack at a current density of $300 \mathrm{~cm}^{2}$ and their results showed that nitrogen crossover from the cathode to the anode increased as air stoichiometry increased. Recently, Hu et al [20] measured liquid water and nitrogen concentration in the anode exhaust of DEA fuel cell stacks and proposed optimized anode purge strategies.

During a DEA operation, water and nitrogen accumulation near the anode outlet can result in very uneven local performance [15, 21, 22]. Yu et al. [15] explored the behaviors of PEMFCs with a dead-ended anode by detecting current distribution and the local potentials and found that the local current density near the outlet decreased gradually during DEA operation. Manokaran et al. [22] measured the spatial-temporal evolution of the local current densities using a commercially available current distribution measurement setup and their results showed that higher current density and thinner membrane led to more serious cell performance fluctuations. Abbou et al. $[21,23]$ investigated local degradation phenomena in a fuel cell during DEA operation, and their results showed that the areas near the outlet suffered more serious degradation compared with the areas near the inlet.

It is obvious from the above that previous studies mainly focused on the overall performance of fuel cells or stack with DEA operations. Some limited studies on local current density are very general. However, the detailed effects of operating conditions on cell performance and its local characteristics with a DEA are still not fully understood. Hence, in this work, an experimental study is conducted to systematically investigate the effects of various key operation parameters, i.e., cathode humidity, air 
stoichiometry, hydrogen pressure and operating current density both at the overall and local levels in a DEA fuel cell. Besides, the evolutions of local current densities at different locations along the anode flow channel are carefully studied to understand how the impurities accumulate and their effects on both cell performance and local characteristics. Under each operating condition, the cell is operated for over 8 hours. The mean purge interval and local current densities are recorded simultaneously.

\section{Experimental}

\subsection{Experimental system}

Fig. 1 (a) shows a schematic of the experimental system. Hydrogen (purity $>99.99 \%$ ) is supplied at the anode and air is supplied at the cathode. A fuel cell test station is used to control air flow rate and air relative humidity at cathode. Cell temperature and operating current density are controlled by the test station. At the anode, a pressure regulator is installed at the inlet to control the gas pressure in the anode channel. A normally-closed solenoid valve is installed at the outlet of the anode to accomplish the DEA operation. The solenoid valve will be opened when the cell voltage decreases by a predetermined amount of $0.1 \mathrm{~V}$.

The experimental fuel cell has an active area of $16 \mathrm{~cm}^{2}$. The fuel cell consists of a Nafion 211 membrane coated with catalyst layers on both sides and two identical gas diffusion layers. The catalyst loading is $0.28 \mathrm{mg} \mathrm{Pt} \mathrm{cm}{ }^{-2}$ on anode and $0.48 \mathrm{mg} \mathrm{Pt}$ $\mathrm{cm}^{-2}$ on cathode, respectively. A pair of graphite flow field plates with identical single serpentine flow field pattern is used. Channel width, channel depth and shoulder width are $2 \mathrm{~mm}, 1 \mathrm{~mm}$ and $2 \mathrm{~mm}$, respectively for the flow field. There are 10 channels and 9 shoulders in every flow field plate. Details of the geometric parameters of the flow field plates are shown in Table 1.

The current distribution measurement gasket technique developed by Sun et al. [24] is used in this study to measure the current distributions and more details of the technique and the measurement method can be found in $[25,26]$. In this study, the measurement gasket is placed between the anode gas diffusion layer and the anode flow field plate to minimize its effect on cell performance. As shown in Fig. 1 (b), the 11 current conducting strips in the measurement gasket are numbered from No. 1 to No. 11, with No. 2 to No. 10 corresponding to the 9 shoulders from the inlet to the outlet. Each of the conducting strips from No. 2 to No. 10 collects current from one shoulder and two half-channels. The currents from strips No.1 and No.11 are also 
collected, but not used in the analyses due to the asymmetry of the areas they cover [24-26]. The local species concentration distribution can be revealed by current distribution measurements. That is to say, high local current densities indicate high hydrogen concentration while low local current densities indicate high nitrogen gas concentration or local liquid water accumulation.

\subsection{Experimental procedure}

Throughout the experiments, the cell operating temperature is maintained at $60^{\circ} \mathrm{C}$ and the cathode backpressure is maintained at atmospheric pressure. The experimental fuel cell is operated under galvanostatic mode. Before a DEA operation, the anode is in flow-through condition for 30 min with the solenoid valve at anode outlet open to remove the initial residual impurities and ensure reproducible DEA initial conditions. Then the solenoid valve is closed and the cell is thus in DEA mode. The cell voltage and local current densities are recorded. When the cell voltage decreases by $0.1 \mathrm{~V}$, the solenoid valve is automatically triggered to open for $0.6 \mathrm{~s}$ for anode purge. The above process is repeated for 8 hours. The value of $0.1 \mathrm{~V}$ is chosen to ensure long enough purge intervals for all the operation conditions used in this study. In real-life applications, the value can be chosen depends on the requirement of the specifica application. The mean purge interval, i.e. the average time between two purge events during the 8 hours, is used as a measure of the rate of impurities accumulation in the following analyses. A high rate of impurities accumulation will result in a short mean purge interval, and vice versa.

\section{Results and discussion}

\subsection{DEA operation}

The experimental fuel cell is operated at a constant current density of $500 \mathrm{~mA}$ $\mathrm{cm}^{-2}$ in DEA operation and the cell voltage and current distribution are measured. Fig. 2 (a) shows the typical time evolutions of fuel cell voltage and local current densities between two successive purge events. Local current distributions along the flow direction at different time are presented in Fig. 2 (b). In Fig.2, two anode purge events are conducted at $0 \mathrm{~min}$ and $33 \mathrm{~min}$ respectively. It can be seen that the initial current density distribution at $0 \mathrm{~min}$ is relatively uniform and the initial cell voltage is $0.54 \mathrm{~V}$. When the solenoid valve is closed, the cell voltage and local current densities maintain relatively constant from 0 to $5 \mathrm{~min}$. After this initial stable period, the cell voltage begins to decrease gradually and eventually decreases to about $0.44 \mathrm{~V}$ at 33 
min. During this period (from 5 to $33 \mathrm{~min}$ ) the local current densities show different variation trends along the channel. In the downstream, e.g. areas from No. 8 to No. 10 , local current densities start to decrease progressively from outlet to upstream. It can be easily seen that current density at No. 10 decreases first, at about $5 \mathrm{~min}$, followed by No. 9 at about $8 \mathrm{~min}$, and then by No. 8 at about $11 \mathrm{~min}$. These results indicate that the impurities accumulate preferentially near the anode outlet and then gradually extend upstream. Since current density at No.10 decreases to nearly zero, severe liquid water flooding must have occurred near the exit of the cell. In the upstream, e.g. areas from No. 2 to No. 6, the local current densities increase to maintain the controlled overall average current density of $500 \mathrm{~mA} \mathrm{~cm}^{-2}$. It can be seen that the transition point is somewhere close to No.7, where the local current density hardly changes during the entire 33 minute period. Finally, the anode purge is triggered at 33 min and the accumulated impurities in the anode are swept out of the gas channel. The local current densities and the cell voltage return to their initial values almost instantaneously.

The evolution of local current densities can be better seen in Fig. 2(b). The current density distribution is relatively uniform right after the anode purge. Then, the current density distribution becomes more and more uneven. Eventually, the cell voltage reaches the threshold value and the anode purge is triggered. It is interesting to note that the slope of cell voltage verses time is very low in the beginning. The slope increases as time progresses and then decreases gradually. In the first a few minutes, there are very small amount of impurities in the anode and their effect on cell performance is negligible. As time progresses, more and more water and nitrogen are transferred to the anode and their effect on cell performance increases. However, as the amount of water and nitrogen in the anode increases, their concentration gradients from cathode to anode decrease. As a results, the rates of water and nitrogen transfer decrease, leading to a slower reduction in cell voltage. It is noted that current density near the inlet is low, due to lower membrane hydration since hydrogen at the inlet is not humidified.

\subsection{Effect of cathode relative humidity}

The effect of cathode inlet gas humidity on the performance of the fuel cell with dead ended anode is studied. Fig. 3 shows the variations of the mean purge intervals as cathode relative humidity increases from $70 \%$ to $100 \%$. It can be seen that the mean purge interval decreases as cathode relative humidity increases, indicating an 
increase in the rate of impurities-accumulations. Obviously, higher cathode relative humidity water concentration in the cathode results in higher water concentration gradient from cathode to anode and leads to higher rate of water transfer. Besides, water content of the membrane increases as cathode relative humidity increases, and as a result, nitrogen crossover from the cathode to the anode can also increase [27].

Current distributions between two successive purge events are also measured under different cathode relative humidity. Fig. 4 (a) shows the current distributions right after the purge. It can be seen that the initial current density distributions are rather uniform and similar for all the humidification levels. Fig. 4 (b) shows the current density distributions at 84 min after an anode purge, which is also the mean purge interval for $100 \%$ cathode humidity. It can be seen that at the same time, higher cathode humidity results in more uneven current distribution. Fig. 4 (c) shows the final current distributions for each of the cathode humidification levels right before their individual anode purge. The results show that the final current density distributions are independent of cathode relative humidity. These results also reveal that as impurities accumulate in the anode channel and the gradients of concentration of hydrogen and impurities along the anode channel are steep.

\subsection{Effect of hydrogen pressure}

Figure 5 shows the variation of the mean purge interval with different inlet hydrogen pressures. It can be seen that the mean purge interval increases from $49 \mathrm{~min}$ to $133 \mathrm{~min}$ as inlet hydrogen pressure increases from 0.2 bar to 0.4 bar, indicating that the rate of the impurities accumulation at the anode decreases with increasing inlet hydrogen pressure. This is mainly due to the increases in water transport from the anode to the cathode by hydraulic permeation, which is proportional to pressure difference between anode and cathode [28]. Thus, the net rate of water transfer from the cathode to the anode is reduced. Besides, nitrogen transfer from cathode to anode may also reduce due to higher adverse pressure gradient.

Figure 6 (a) shows the current distributions right after the purge, Fig.6 (b) the current distributions at $49 \mathrm{~min}$, the mean purge interval at 0.2 bar anode pressure, and Fig.6 (c) the current distributions just before the purge for different inlet hydrogen pressures. These results are very similar to those at different cathode relative humidity. Thus, the concentration profiles of hydrogen, nitrogen and water and impurities along the anode channel are also independent of anode pressure at the same relative stages. 


\subsection{Effect of air stoichiometry}

Figure 7 shows the variation of the mean purge interval with different air stoichiometry. It can be seen that the mean purge interval increases from 29 min to 114 min with air stoichiometry increasing from 1.5 to 2.5 , indicating that the rate of impurities accumulation in the anode decreases with increasing air flow rate, consistent with the result in the literature [14]. Higher air flow rate can remove water out of the cathode more effectively. Therefore, the water-concentration gradient from the cathode to the anode is reduced and water diffusion rate from the cathode to the anode decreases. It is also clear from Fig.7 that the rate of increase in the mean purge interval with air stoichiometry decreases, and further increase in air stoichiometry from 2.5 to 3.0 has no apparent effect on the mean purge interval. When air stoichiometry increases to 2.5 , most of the excess water can be removed effectively from the cathode and further increase in air flow rate cannot significantly reduce water content in the cathode since the inlet air is at $100 \%$ relative humidity.

Figure 8 shows (a) the current density distributions right after the purge, and (b) the current distributions just before the next purge with different air stoichiometry. It can be seen that the initial current density distributions are similar for the different air stoichiometry, except at air stoichiometry of 1.5 , where the higher current density is higher in the upstream and lower in the downstream, indicating the effect of decreasing oxygen concentration along the flow direction in the cathode [24, 29].

It is interesting to note that, just before the purges, the slopes of current density decrease in the downstream for lower air stoichiometry are lower. Since such a trend is opposite to the effect of decreasing oxygen concentration in the cathode side, it must be caused by the anode side. Since water vapor partial pressure cannot be greater than its local saturation pressure, the general trend of steep decrease in current density must be caused by the increasing concentration of nitrogen along the flow direction in the anode. Thus, just before purging, at lower air stoichiometry, there is less nitrogen in the anode than at higher air stoichiometry. The lower nitrogen concentration in the anode is mainly due to the shorter mean purging interval. However, this phenomenon indicates that the rates of net water and nitrogen transfer from the cathode to the anode must change differently with air stoichiometry.

\subsection{Effect of operating current density}

Figure 9 shows the variation of the mean purge interval with different operating current densities. It can be seen that the mean purge interval decreases from $143 \mathrm{~min}$ 
to $36 \mathrm{~min}$ as operating current density increases from $300 \mathrm{~mA} \mathrm{~cm}^{-2}$ to $600 \mathrm{~mA} \mathrm{~cm}^{-2}$. It is also interesting to note that the rate of decrease in the mean purge interval is reduced as operating current density increases. The result indicates that the impurities accumulation in the anode increases with increasing current density; but the rate of increase slows down gradually. This phenomenon can be explained with the net water flux across the membrane. As operating current density increases, the water production rate increases, which leads to increase in the water concentration gradient across the membrane. With the increased water concentration gradient, the water diffusion from the cathode to the anode increases. Besides, rate of nitrogen transfer also increase with water content in the membrane. On the other hand, water transfer from the anode to the cathode due to electro-osmotic drag also increases with increasing current density [28]. In the low current density region, the diffusion water transport increases faster with current density than that due to electro-osmotic drag, resulting in increasing net impurity transfer from cathode to anode. In the high current density region, the reverse trend is observed [30], but the net impurity transfer still increases with current density even though the rate decreases within the current density range in this study. With the complex change in water diffusion and electro-osmotic drag across the membrane, the impurities accumulation in the anode increases when operating current density increases, but the rate of increase decreases gradually.

\section{Conclusion}

Effects of operating conditions on both overall and local performances of PEM fuel cells with dead-ended anode are systematically studied. Based on the experiments results, following conclusions can be made:

- Operating conditions have significant effects on water and nitrogen transfer in PEM fuel cells with a dead-ended anode.

- Local current densities change differently at different locations during impurity accumulations.

- Impurities accumulate first at the end of the anode channel and progress gradually upstream.

- The concentration gradients of hydrogen and impurities along the anode channel are steep before purges.

- Rates of impurities transfer increase with the increase in cathode inlet humidity and operating current density, while the rates decrease with 
hydrogen pressure and air stoichiometry up to a certain value.

\section{Acknowledge}

The financial supports from the National Science Foundation of China for Creative Research Groups (No. 51121092) are gratefully acknowledged.

\section{References}

[1] Wang Y, Chen KS, Mishler J, Cho SC, Adroher XC. A review of polymer electrolyte membrane fuel cells: Technology, applications, and needs on fundamental research. Applied Energy. 2011;88:981-1007.

[2] Hikita S, Nakatani F, Yamane K, Takagi Y. Power-generation characteristics of hydrogen fuel cell with dead-end system. Jsae Review. 2002;23:177-82.

[3] Lee Y, Jang YH, Jung T, Chung JT, Kim Y. Performance Characteristics of a Polymer Electrolyte Fuel Cell with the Anodic Supply Mode. ECS Transactions. 2006;3:871-8.

[4] Hwang J-J. Effect of hydrogen delivery schemes on fuel cell efficiency. Journal of Power Sources. 2013;239:54-63.

[5] Chen B, Ke W, Luo M, Wang J, Tu Z, Pan M, et al. Operation characteristics and carbon corrosion of PEMFC (Proton exchange membrane fuel cell) with dead-ended anode for high hydrogen utilization. Energy. 2015;91:799-806.

[6] Meyer Q, Ashton S, Curnick O, Reisch T, Adcock P, Ronaszegi K, et al. Dead-ended anode polymer electrolyte fuel cell stack operation investigated using electrochemical impedance spectroscopy, off-gas analysis and thermal imaging. Journal of Power Sources. 2014;254:1-9.

[7] Chen Y-S, Yang C-W, Lee J-Y. Implementation and evaluation for anode purging of a fuel cell based on nitrogen concentration. Applied Energy. 2014;113:1519-24.

[8] Nikiforow K, Karimaki H, Keranen TM, Ihonen J. Optimization study of purge cycle in proton exchange membrane fuel cell system. Journal of Power Sources. 2013;238:336-44.

[9] Siegel JB, McKay DA, Stefanopoulou AG, leee. Modeling and validation of fuel cell water dynamics using neutron imaging. 2008 American Control Conference, Vols 1-122008. p. 2573-8.

[10] Himanen O, Hottinen T, Tuurala S. Operation of a planar free-breathing PEMFC in a dead-end mode. Electrochemistry Communications. 2007;9:891-4.

[11] Dumercy L, Péra MC, Glises R, Hissel D, Hamandi S, Badin F, et al. PEFC Stack Operating in Anodic Dead End Mode. Fuel Cells. 2004;4:352-7.

[12] Chevalier S, Ge N, Lee J, Antonacci P, Yip R, George MG, et al. In situ analysis of voltage degradation in a polymer electrolyte membrane fuel cell with a dead-ended anode. Electrochemistry Communications. 2015;59:16-9.

[13] Siegel JB, Bohac SV, Stefanopoulou AG, Yesilyurt S. Nitrogen Front Evolution in Purged Polymer Electrolyte Membrane Fuel Cell with Dead-Ended Anode. Journal of the Electrochemical Society. 2010;157:B1081-B93.

[14] Lee Y, Kim B, Kim Y. An experimental study on water transport through the membrane of a PEFC operating in the dead-end mode. International Journal of Hydrogen Energy. 2009;34:7768-79. 
[15] Jianliang Y, Zuwei J, Ming H, Dong L, Yu X, Meiling D, et al. Analysis of the behavior and degradation in proton exchange membrane fuel cells with a dead-ended anode. Journal of Power Sources. 2014;246:90-4.

[16] Matsuura T, Chen J, Siegel JB, Stefanopoulou AG. Degradation phenomena in PEM fuel cell with dead-ended anode. International Journal of Hydrogen Energy. 2013;38:11346-56.

[17] Baumgartner WR, Parz P, Fraser SD, Wallnoefer E, Hacker V. Polarization study of a PEMFC with four reference electrodes at hydrogen starvation conditions. Journal of Power Sources. 2008;182:413-21.

[18] Siegel JB, McKay DA, Stefanopoulou AG, Hussey DS, Jacobson DL. Measurement of liquid water accumulation in a PEMFC with dead-ended anode. Journal of the Electrochemical Society. 2008;155:B1168-B78.

[19] Sasmito AP, Ali MI, Shamim T. A Factorial Study to Investigate the Purging Effect on the Performance of a Dead-End Anode PEM Fuel Cell Stack. Fuel Cells. 2015;15:160-9.

[20] Hu Z, Yu Y, Wang G, Chen X, Chen P, Chen J, et al. Anode purge strategy optimization of the polymer electrode membrane fuel cell system under the dead-end anode operation. Journal of Power Sources. 2016;320:68-77.

[21] Abbou S, Dillet J, Spernjak D, Mukundan R, Borup RL, Maranzana G, et al. High Potential Excursions during PEM Fuel Cell Operation with Dead-Ended Anode. Journal of The Electrochemical Society. 2015;162:F1212-F20.

[22] Manokaran A, Pushpavanam S, Sridhar P, Pitchumani S. Experimental analysis of spatio-temporal behavior of anodic dead-end mode operated polymer electrolyte fuel cell. Journal of Power Sources. 2011;196:9931-8.

[23] Abbou S, Dillet J, Spernjak D, Mukundan R, Fairweather JD, Borup RL, et al. Time Evolution of Local Potentials during PEM Fuel Cell Operation with Dead-Ended Anode. ECS Transactions. 2013;58:1631-42.

[24] Sun H, Zhang G, Guo L-J, Liu H. A novel technique for measuring current distributions in PEM fuel cells. Journal of Power Sources. 2006;158:326-32.

[25] Zhang G, Guo L, Ma B, Liu H. Comparison of current distributions in proton exchange membrane fuel cells with interdigitated and serpentine flow fields. Journal of Power Sources. 2009;188:213-9.

[26] Sun H, Zhang G, Guo L, Liu H. A Study of dynamic characteristics of PEM fuel cells by measuring local currents. International Journal of Hydrogen Energy. 2009;34:5529-36.

[27] Baik KD, Kim MS. Characterization of nitrogen gas crossover through the membrane in proton-exchange membrane fuel cells. International Journal of Hydrogen Energy. 2011;36:732-9.

[28] Husar A, Higier A, Liu H. In situ measurements of water transfer due to different mechanisms in a proton exchange membrane fuel cell. Journal of Power Sources. 2008;183:240-6.

[29] Zhang G, Guo L, Ma L, Liu H. Simultaneous measurement of current and temperature distributions in a proton exchange membrane fuel cell. Journal of Power Sources. 2010;195:3597-604.

[30] Cai Y, Hu J, Ma H, Yi B, Zhang H. Effect of water transport properties on a PEM fuel cell operating with dry hydrogen. Electrochimica Acta. 2006;51:6361-6.

\section{List of Tables}

Table. 1. Physical parameters of the experimental fuel cell. 


\section{List of Figures}

Fig. 1. (a) Schematic of the experimental system. (b) Photograph of the current distribution measurement gasket.

Fig. 2. (a) Time evolutions of local current densities and the fuel cell voltage. (b) Current distribution along the anode channel at different time during DEA operation.

Fig. 3. Variation of mean purge interval with cathode relative humidity.

Fig. 4. Current distributions at different cathode inlet relative humidity: (a) initial current distributions after the purge; (b) current distributions at $\mathrm{t}=84 \mathrm{~min}$, (c) current distributions just before the purge.

Fig. 5. Variation of mean purge interval with inlet hydrogen pressures.

Fig. 6. Current distributions at different inlet hydrogen pressures: (a) initial current distributions after the purge, (b) current distributions at $\mathrm{t}=49 \mathrm{~min}$, (c) current distributions just before the purge.

Fig. 7. Variation of mean purge interval with air stoichiometry.

Fig. 8. Current distributions at different air stoichiometry: (a) initial current distributions after the purge, (b) current distributions just before the purge.

Fig. 9. Variation of mean purge interval with operating current density.

Table. 1.

Table 1-Physical parameters of the experimental fuel cell

Channel length (mm)

Channel width (mm)

Channel depth (mm)

Shoulder width (mm)

Number of channels

Number of shoulders

MEA active area $\left(\mathrm{cm}^{2}\right)$

Membrane thickness (mm)

GDL thickness (mm)

Anode catalyst loading $\left(\mathrm{mg} / \mathrm{cm}^{2}\right)$

Cathode catalyst loading $\left(\mathrm{mg} / \mathrm{cm}^{2}\right)$
39

2

1

2

10

9

$4 \times 4$

0.025

0.22

0.28

0.48 


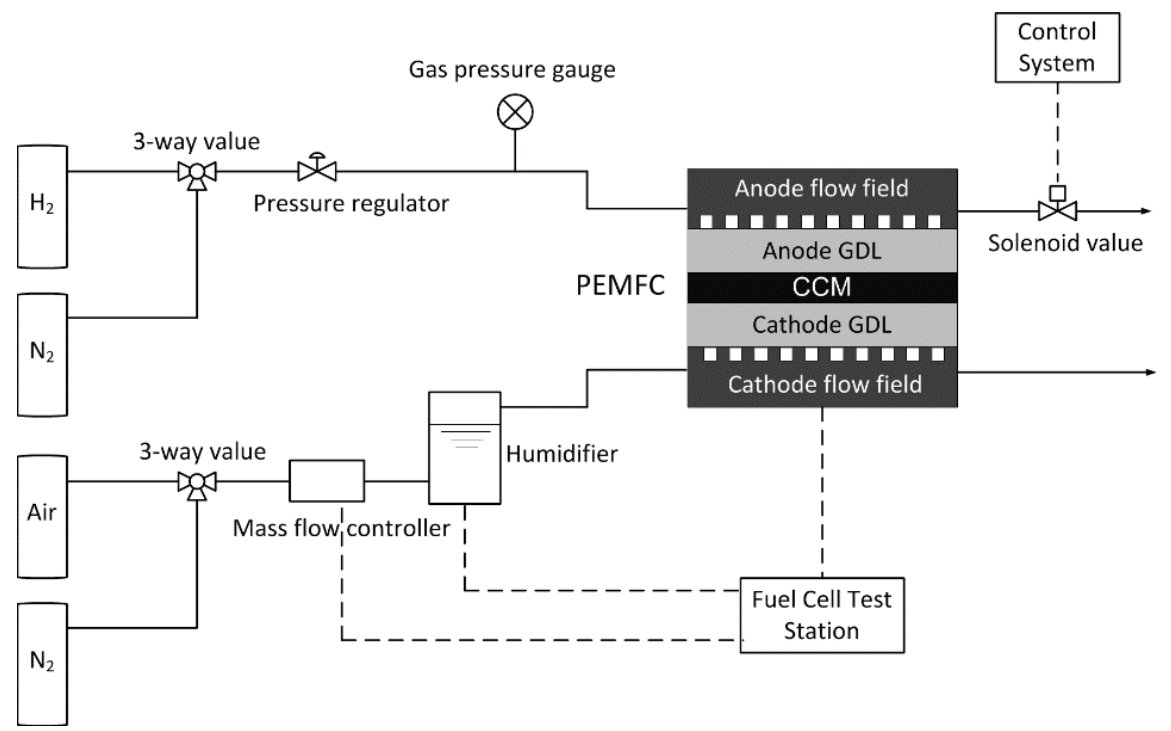

(a)

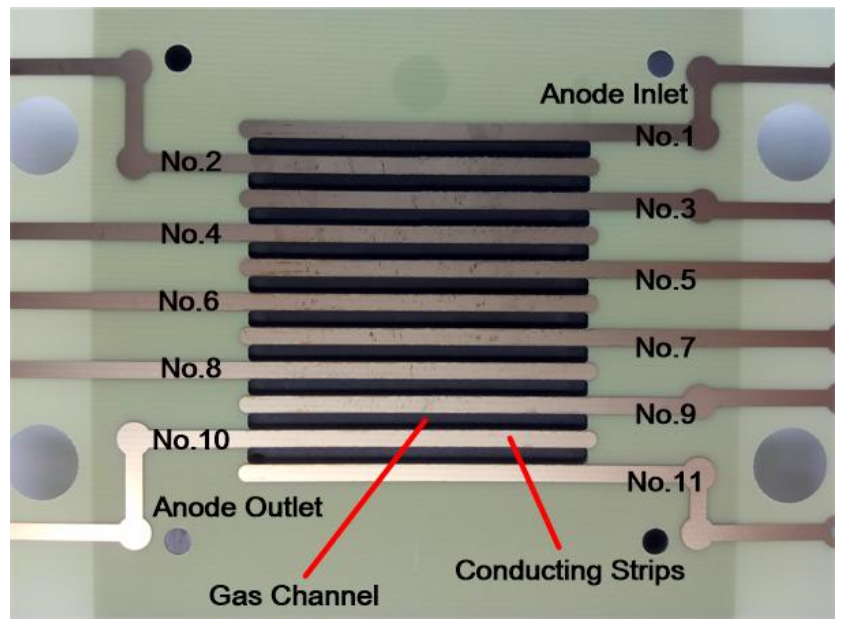

(b)

Fig. 1. (a) Schematic of the experimental system. (b) Photograph of the current distribution measurement gasket. 


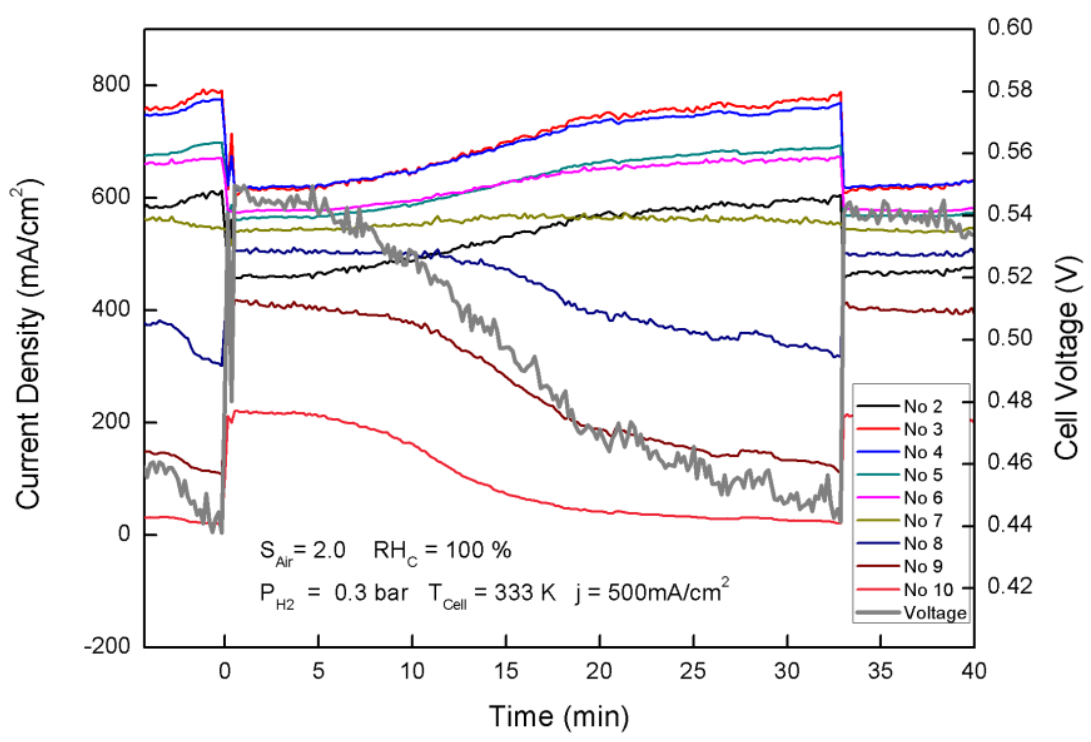

(a)

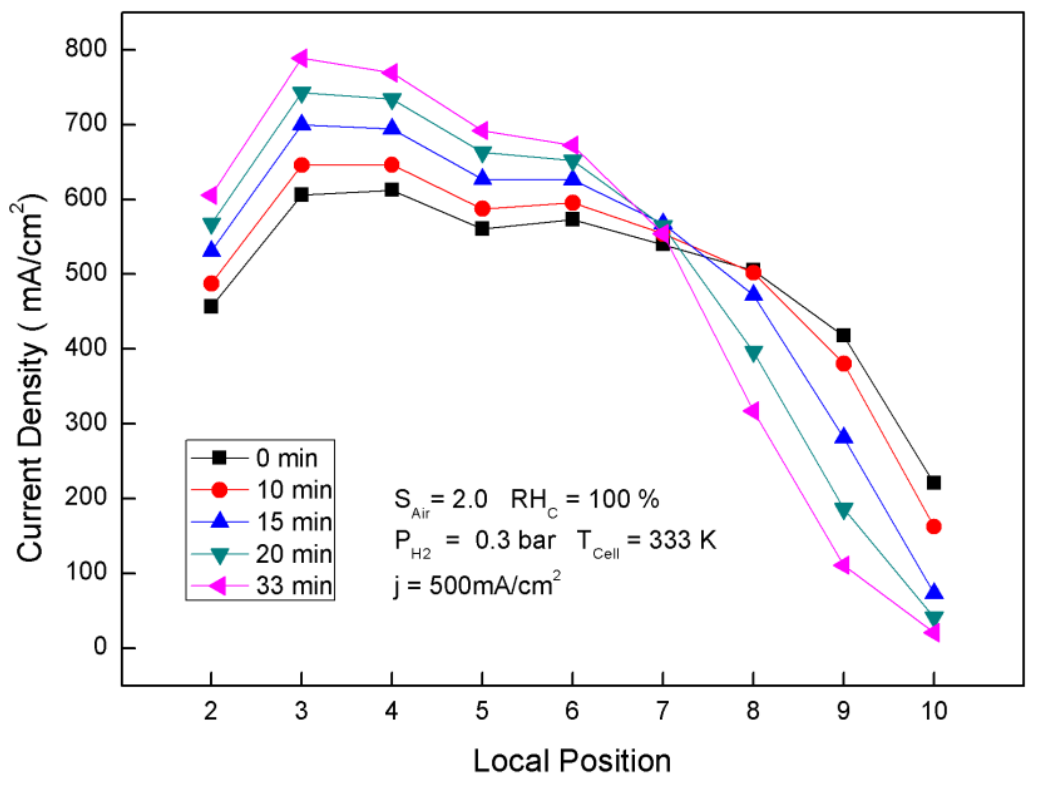

(b)

Fig. 2. (a) Time evolutions of local current densities and the fuel cell voltage. (b)

Current distribution along the anode channel at different time during DEA operation. 


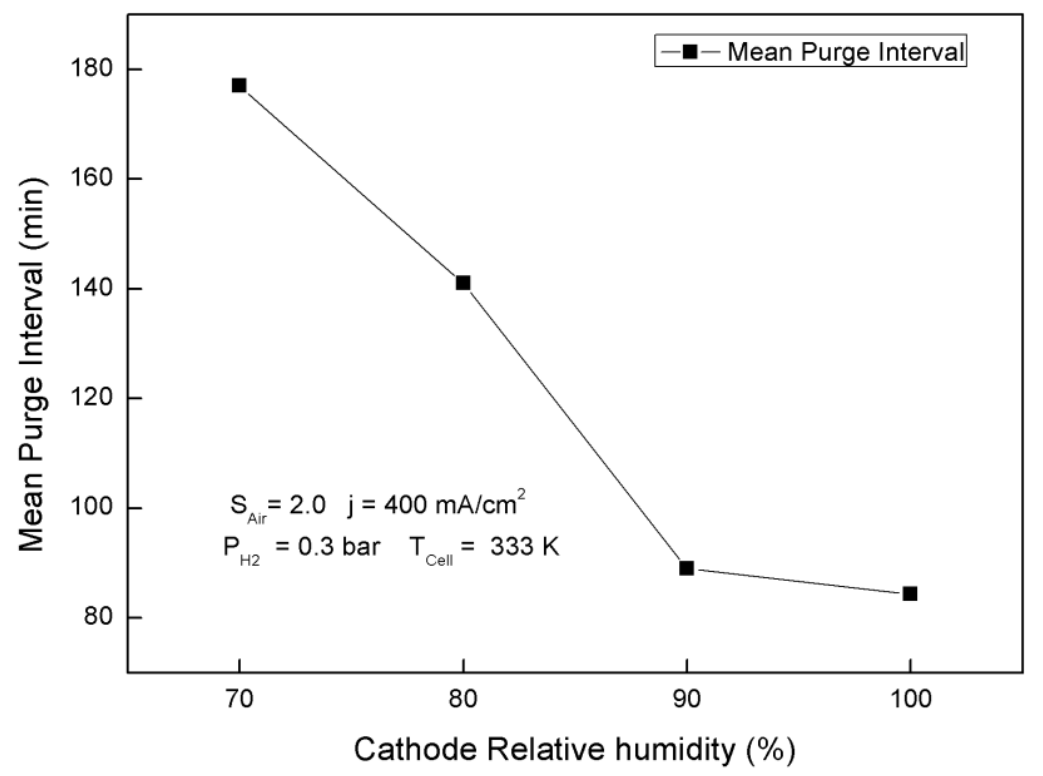

Fig. 3. Variation of mean purge interval with cathode relative humidity. 


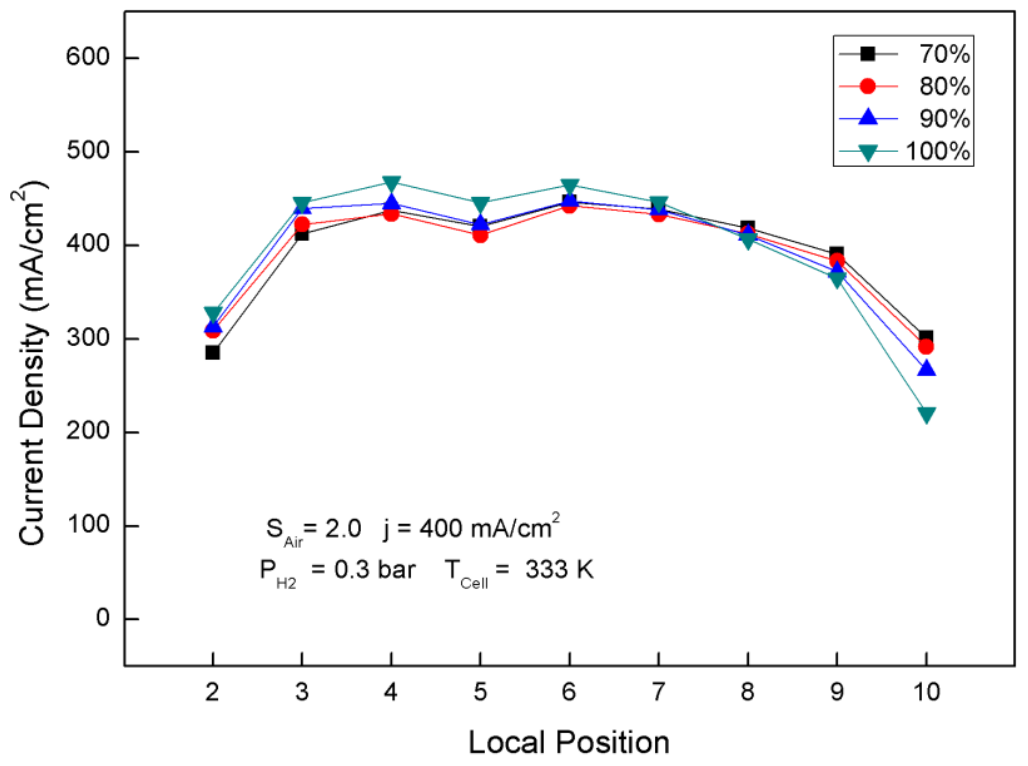

(a)

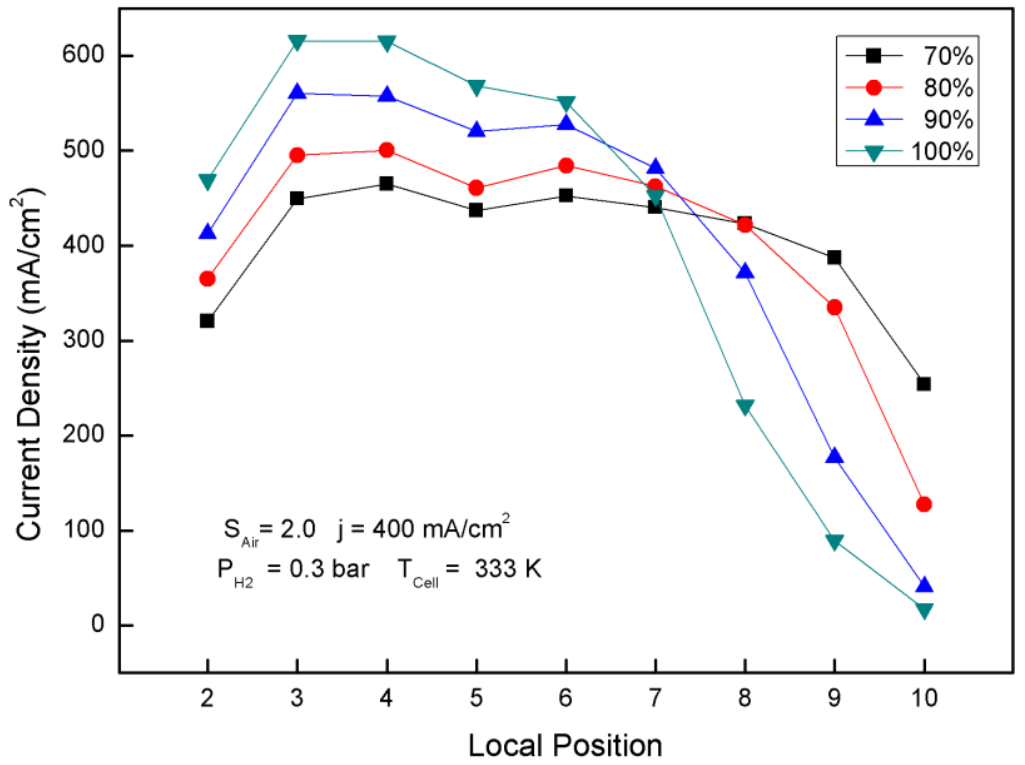

(b) 


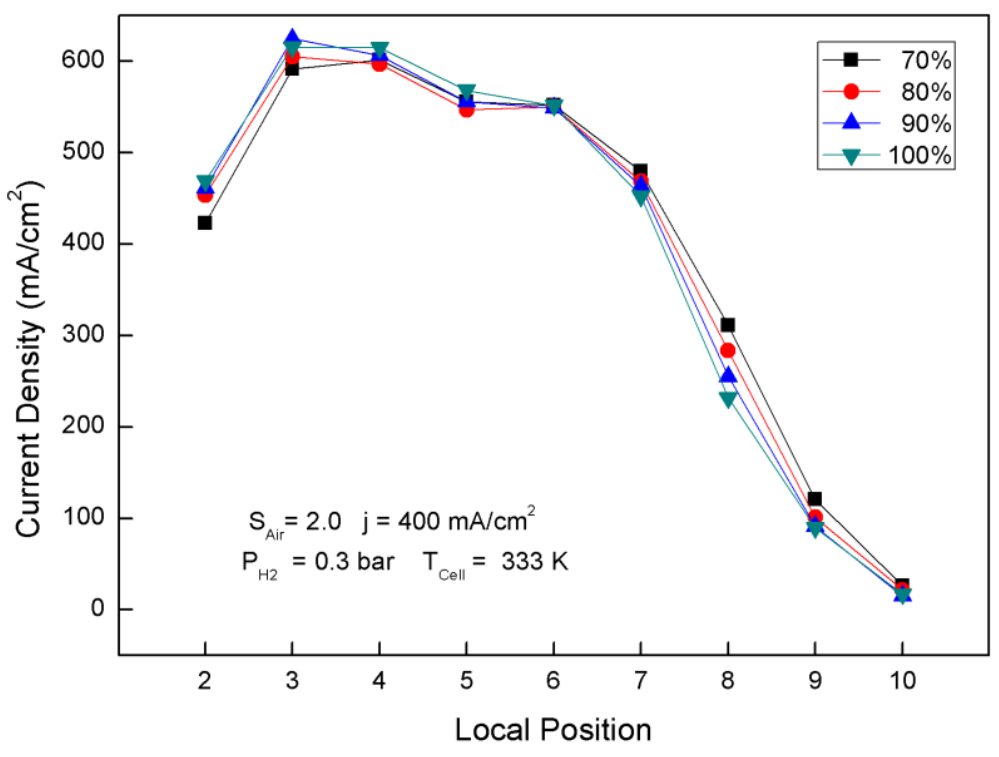

(c)

Fig. 4. Current distributions at different cathode inlet relative humidity: (a) initial current distributions after the purge; (b) current distributions at $t=84 \mathrm{~min}$, (c) current distributions just before the purge. 


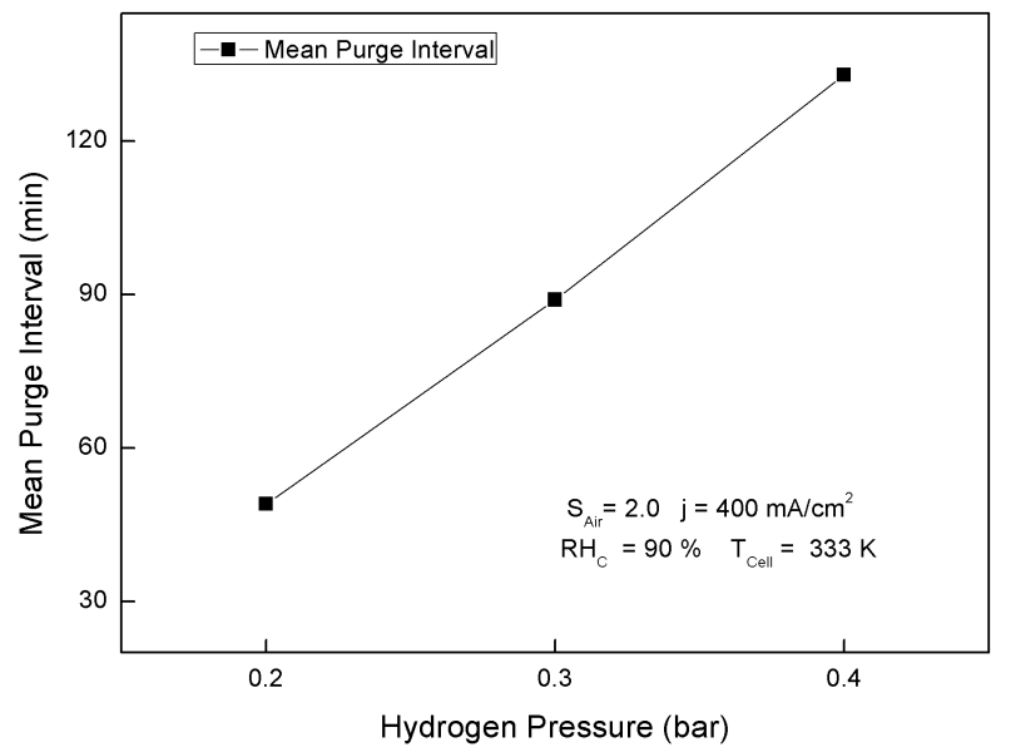

Fig. 5. Variation of mean purge interval with inlet hydrogen pressures. 


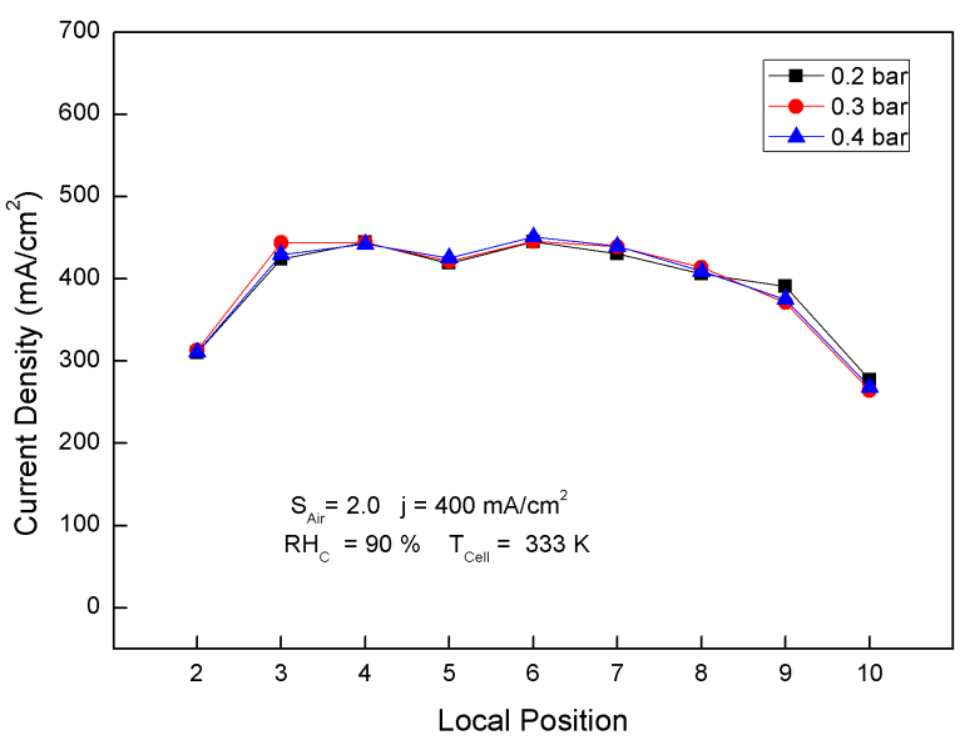

(a)

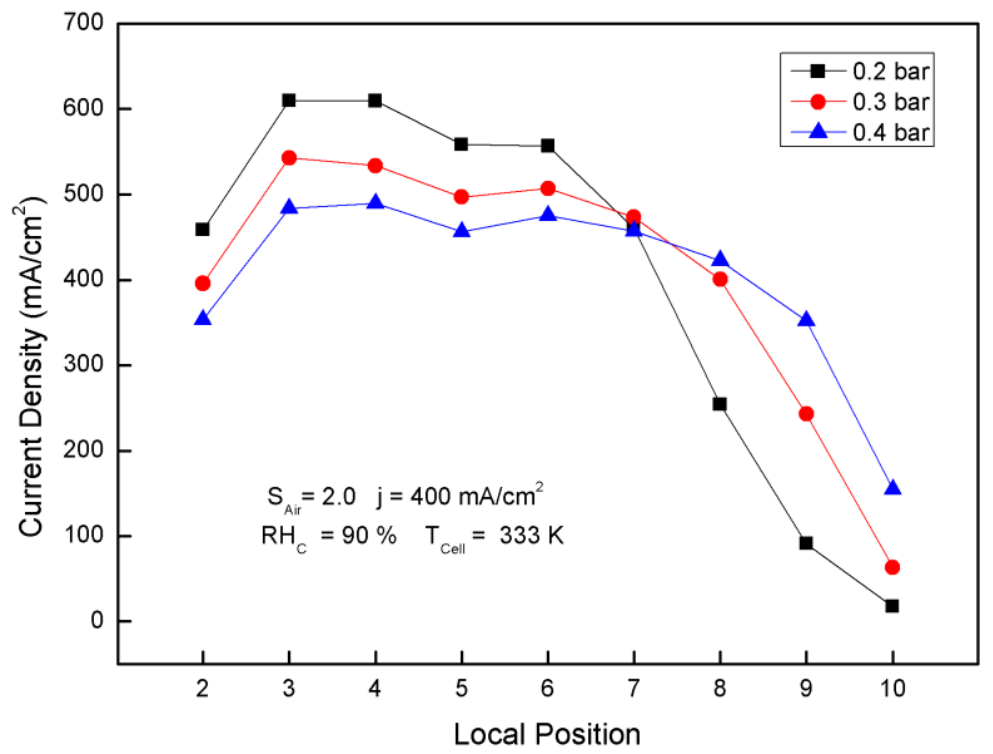

(b) 


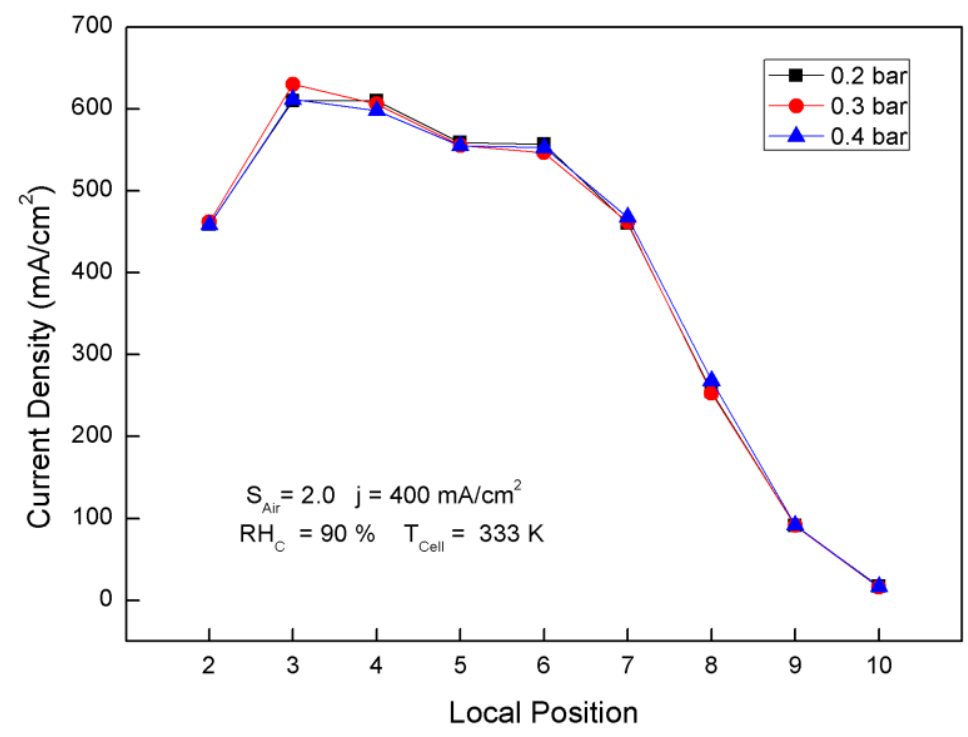

(c)

Fig. 6. Current distributions at different inlet hydrogen pressures: (a) initial current distributions after the purge, (b) current distributions at $\mathrm{t}=49 \mathrm{~min}$, (c) current distributions just before the purge. 


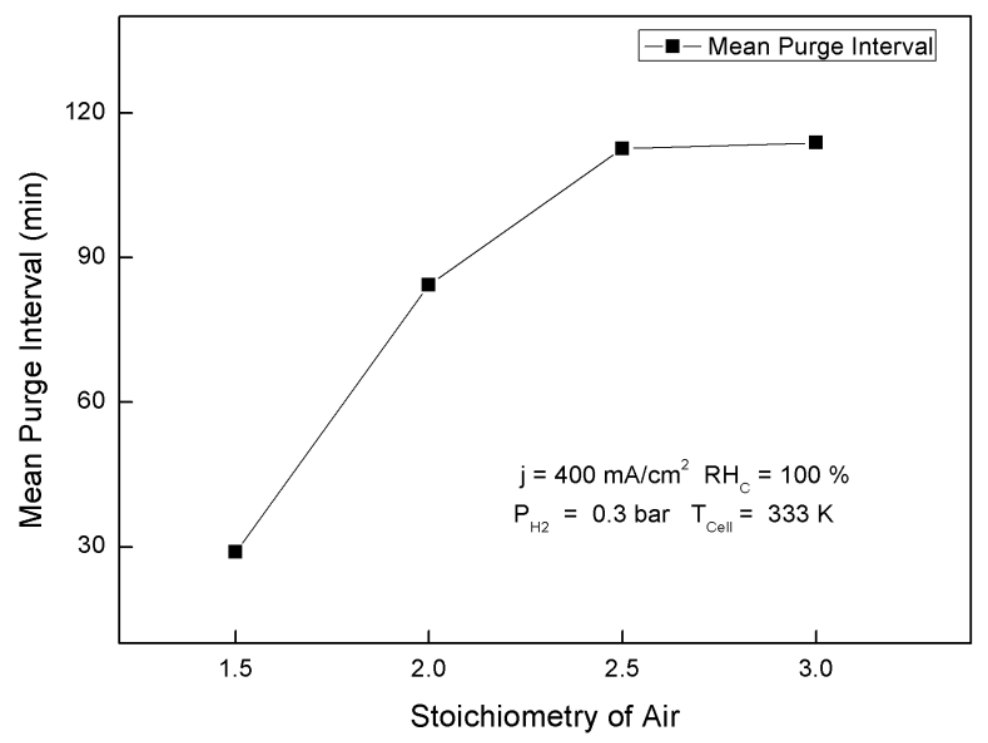

Fig. 7. Variation of mean purge interval with air stoichiometry. 


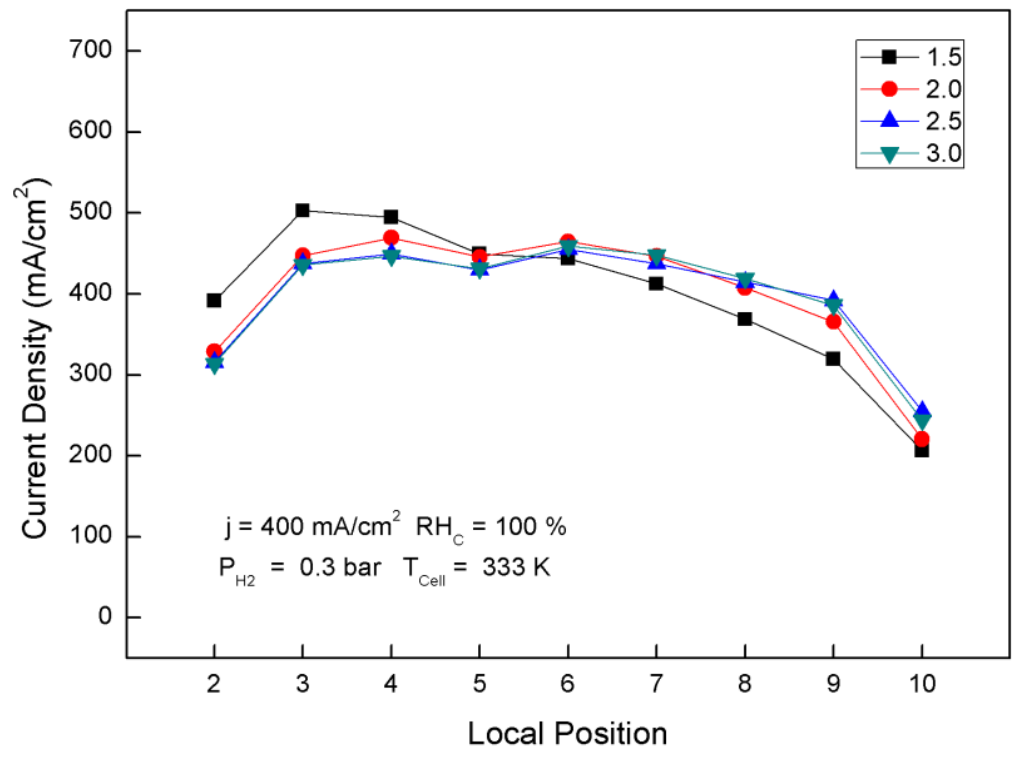

(a)

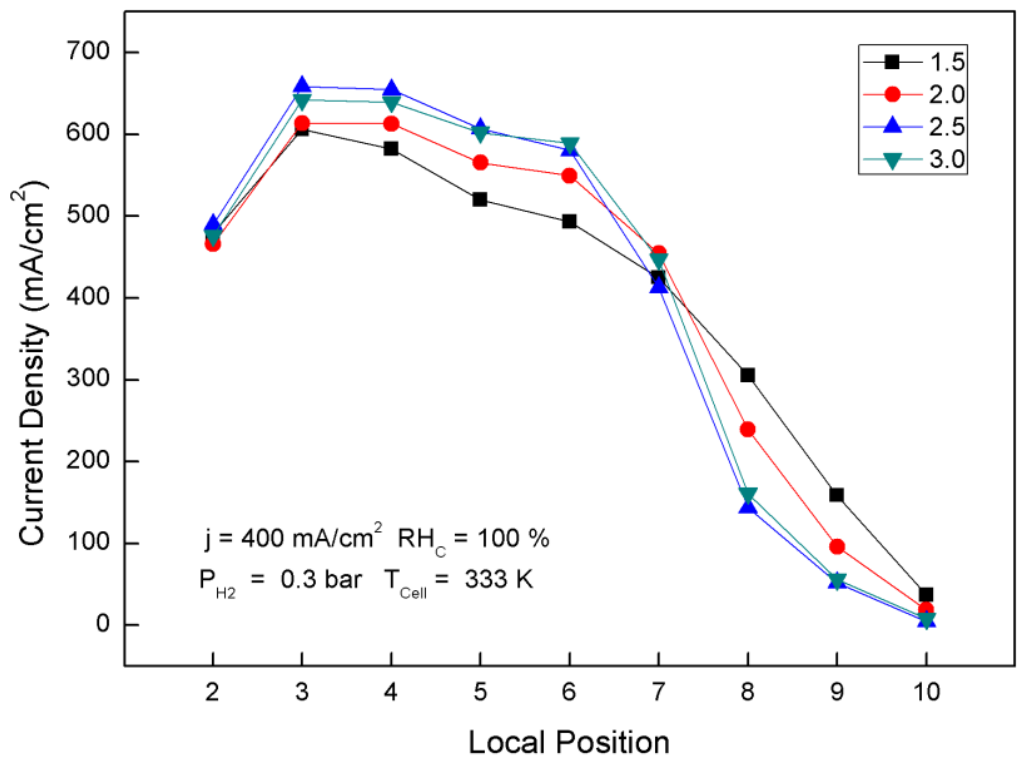

(b)

Fig. 8. Current distributions at different air stoichiometry: (a) initial current distributions after the purge, (b) current distributions just before the purge. 


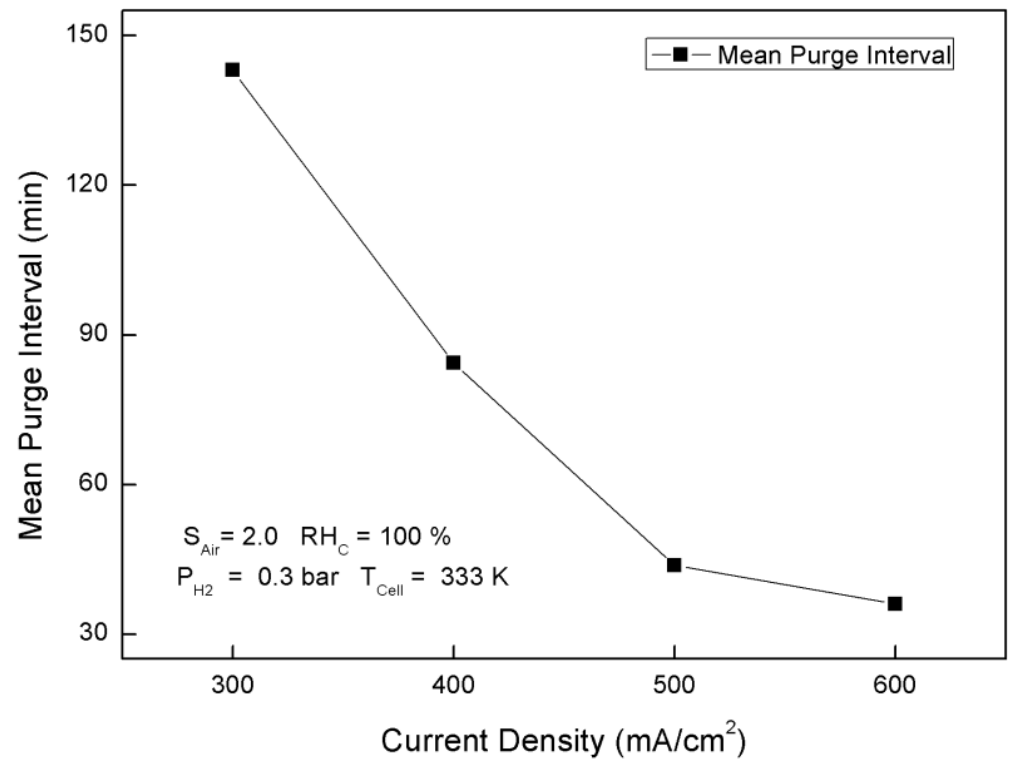

Fig. 9. Variation of mean purge interval with operating current density. 